\title{
ROLE OF SIMVASTATIN AND ALLIUM SATIVUM ON LIPID PROFILE IN DIABETIC DYSLIPIDEMIC PATIENTS: A COMPARATIVE STUDY.
}

1. MBBS, M. Phil, P.hD

Associate Professor Biochemistry, United Medical \& Dental College, Karachi, Pakistan.

2. Final year student, UMDC United Medical \& Dental College, Karachi, Pakistan.

3. MBBS, M.Phil

Associate Professor Anatomy, United Medical \& Dental College Karachi, Pakistan

4. Final Year Student, UMDC United Medical \& Dental College, Karachi, Pakistan.

5. Final Year Student, UMDC United Medical \& Dental College, Karachi, Pakistan

Correspondence Address: Dr. Naveed Ali Siddiqui Associate professor,

Department of biochemistry. United Medical \& Dental College, Karachi.

naveed_sddq@yahoo.com

Article received on: 25/07/2019

Accepted for publication: 15/10/2019
Naveed Ali Siddiqui ${ }^{1}$, Fatima Bint Taj ${ }^{2}$, Imran Ishaque ${ }^{3}$, Ayesha Shahid ${ }^{4}$, Ayesha Ayaz $^{5}$

ABSTRACT...Objectives: To evaluate the changes in lipid profile in patients with diabetic dyslipidemia using lipid lowering drug, simvastatin and herbal product allium sativum. Study Design: Clinical trial. Setting: Surgeon Munawar Memorial Hospital, Karachi. Period: $1^{\text {st }}$ January 2017 to $30^{\text {th }}$ April 2017. Material \& Methods: The study was designed to assess the effects of HMG Co-A reductase inhibitor (simvastatin) and allium sativum on lipid profile in patients with diabetic dysplipidemia. The exclusion criteria included lactating/pregnant women's, renal, liver and established coronary artery disease. Results: Sixty patients with abnormal lipid profile were included in the study (age 30-60 years). Patients were divided into two groups (30 patients each). Group a was orally administered with product of simvastatin $(20 \mathrm{mg}) /$ day for 04 months and in group b, patients were orally administered with herbal product of allium sativum (300 $\mathrm{mg}$ )/day for 04 months. Conclusion: On the basis of this study it is observed that allium sativum as well as simvastatin tablets both reduce total cholesterol, low density lipoprotein cholesterol (LDL-C) and increase high density lipoprotein cholesterol (HDL-C).

Keywords: $\quad$ Allium Sativum, Dyslipidemia, Lipid Profile, Simvastatin.

Article Citation: Siddiqui NA, Taj FB, Ishaque I, Shahid A, Ayaz A. Role of simvastatin and allium sativum on lipid profile in diabetic dyslipidemic patients: $A$ comparative study. Professional Med J 2020; 27(2):353-358.

DOI: 10.29309/TPMJ/2020.27.2.3974

\section{INTRODUCTION}

CVD is the chief reason of disability among the population and act as a factor to the growing expenditure of health related problems. $^{1}$ it has been earlier proved that chronic increase level of diabetes is correlated with dysfunction, impairment and finally failure of organs, especially the heart, nerves, kidneys, blood vessels and eyes. About half of the diabetic patients suffer with these complications. ${ }^{2}$ Diabetes mellitus causes important changes such as dyslipidemia, and disturbance in the metabolism of lipids, carbohydrates, and proteins..$^{3,4}$ it is reported that by the year of 2015, cardiovascular artery disease will be responsible for 20 million deaths approximately, mainly from strokes and heart attacks. ${ }^{5}$ some of the contributing factors commonly correlated with the evolution of atherosclerosis and cardiovascular diseases include elevated lipid profile, high blood pressure and diabetes mellitus, $, 6,7,9$ tobacco use, obesity, ${ }^{10}$ physical inactivity. ${ }^{11}$ Major common elements for development of cardiac ischemia and acute coronary artery diseases are continuously rising in pakistan. Ratio of macro-vascular disease in pakistan is ascending as in western world. ${ }^{12}$ Lipid decreasing drugs for the treatment of hyperlipidemia include statins (3-hydroxy-3methylglutaryl coenzyme a reductase inhibitors), fibrates, nicotinic acid, and bile acid binding sequestrants. The drugs used in diabetic dyslipidemia contain simvastatin. These drugs contain $5 \mathrm{mg}, 10 \mathrm{mg}, 20 \mathrm{mg}$, and $40 \mathrm{mg}$ of simvastatin. Simvastatin have reported to be especially effective in decreasing the level of low-density lipoprotein (LDL-C) cholesterol and, to a lesser extent, that of triglycerides. ${ }^{13,14}$ The HMG-CoA reductase inhibitors are drug of choice for decreasing LDL-C in diabetic dyslipidemic patients. ${ }^{15,16}$ Allium sativum has been used for the past fewer years as both food and medicine in human populations. ${ }^{17,18,19}$ Allium sativum used as a cholesterol lowering agent, but efficacy confusing results. Many of the clinical trials and 
studies showed no significant effects of allium sativum supplements on serum lipids profile. ${ }^{20}$

\section{MATERIAL AND METHODS Patient's Selection:}

The population under study was representative of Pakistani population with diabetic dyslipidemia. The study period consist of 4 months. Blood pressure, body weight and height of subjects were assessed. The patient answered the questionnaire on health complaints, smoking, social role, drug usage, family history and dietary pattern. Patients were asked to fill a consent form before starting the experiment. The initial inclusion criteria of the patient were 1) age between old of either sex, 2) patients with diabetic dyslipidemia. The exclusion criteria were 1) pregnancy or lactation, 2) patients with liver diseases, 3) patients with renal diseases. Detailed medical history and physical examination of all patients were carried out.

\section{Study design:}

Sixty patients were selected for the study. Serum lipid profile was done before and after the treatment. Patients were orally administered with product of simvastatin $(20 \mathrm{mg}) /$ day and herbal product of allium sativum (300 mg/day) for 04 months. After 04 months, blood samples were collected again for the estimation of lipid profile.

\section{Collection of Samples}

The blood sample was drawn using $5 \mathrm{ml}$ syringe and centrifuged at $3000 \mathrm{rpm}$ for 10 minutes. Serum was separated and collected in clean and dry eppendorfs and was stored at $-70 \mathrm{c}$ till further analysis.

\section{Biochemical Analysis}

The serum levels of total cholesterol, tg, and hdl were determined enzymatically on microlab using commercially available (randox laboratories limited, UK) kits. LDL was calculated using friedwald formula.

\section{Statistical Analysis}

The data was analyzed statistically using spss version-11.

\section{RESULTS}

In the present study 60 patients were investigated for the lipid lowering activity of the international product of simvastatin and herbal product of allium sativum with diabetic dyslipidemia. They were divided into group I and II.

The individual of group i consist of 30 patients were orally administered with product of simvastatin (20mg)/day for 4 months and group II consist of other 30 patients were orally administered with herbal product of allium sativum (300mg)/day for 4 months. Figure 1 and 2 represents the variation of serum lipids including cholesterol, high density lipoprotein (HDL), triglyceride (TG) and low density lipoprotein (LDL) in diabetic dyslipidemia before and after 4 months of treatment with product of simvastatin and herbal product of allium sativum.

Patients who have been given simvastatin at a dose of $20 \mathrm{mg} /$ day showed a reduction in total cholesterol from baseline value of 232.53 to \pm $6.72 \mathrm{mg} / \mathrm{dl}$ to 189.76 to $\pm 5.46 \mathrm{mg} / \mathrm{dl}$ at month 04 . This decreases was found to be statistically highly significant $(p<0.005)$ when compared from before and after treatment.

Patients who have been given simvastatin at a dose of $20 \mathrm{mg} /$ day showed a reduction in serum triglyceride from baseline value of 207.26 to \pm $10.22 \mathrm{mg} / \mathrm{dl}$ to 182.20 to $\pm 8.72 \mathrm{mg} / \mathrm{dl}$ at month 04 . This decreases was found to be statistically highly significant $(p<0.005)$ when compared from before and after treatment. Patients who have been given simvastatin at a dose of $20 \mathrm{mg} /$ day showed an increase in serum high density lipoprotein (HDL) from baseline value of 32.33 to $\pm 0.87 \mathrm{mg} / \mathrm{dl}$ to 34.76 to $\pm 0.92 \mathrm{mg} / \mathrm{dl}$ at month 04 . This increases was found to be statistically highly significant $(p<0.005)$ when compared from before and after treatment.

Patients who have been given simvastatin at a dose of $20 \mathrm{mg} /$ day showed a reduction in serum low density lipoprotein (LDL) from baseline value of 183.93 to $\pm 7.14 \mathrm{mg} / \mathrm{dl}$ to 146.60 to \pm 5.30 $\mathrm{mg} / \mathrm{dl}$ at month 04 . This decreases was found to be statistically highly significant $(p<0.005)$ when compared from before and after treatment. 
Patients who have been given allium sativum at a dose of $300 \mathrm{mg} /$ day showed a reduction in total cholesterol from baseline value of 225.86 to \pm 4.22 $\mathrm{mg} / \mathrm{dl}$ to 207.96 to $\pm 4.69 \mathrm{mg} / \mathrm{dl}$ at month 04 . This decreases was found to be statistically significant $(p<0.05)$ when compared from before and after treatment. Patients who have been given allium sativum at a dose of $300 \mathrm{mg} /$ day showed baseline value of serum triglyceride from 191.10 to \pm 6.92 $\mathrm{mg} / \mathrm{dl}$ to 194.30 to $\pm 7.20 \mathrm{mg} / \mathrm{dl}$ at month 04 . This was not significant when compared from before and after treatment.

Patients who have been given allium sativum at a dose of $300 \mathrm{mg} /$ day showed an increase in serum high density lipoprotein (HDL) from baseline value of 35.46 to $\pm 0.59 \mathrm{mg} / \mathrm{dl}$ to 38.00 to $\pm 0.57 \mathrm{mg} / \mathrm{dl}$ at month 04 . This increases was found to be statistically significant $(p<0.05)$ when compared from before and after treatment. Patients who have been given allium sativum at a dose of $300 \mathrm{mg} /$ day showed a reduction in serum low density lipoprotein (LDL) from baseline value of 158.30 to $\pm 3.22 \mathrm{mg} / \mathrm{dl}$ to 138.63 to $\pm 3.10 \mathrm{mg} /$ $\mathrm{dl}$ at month 04 . This decreases was found to be statistically significant $(p<0.05)$ when compared from before and after treatment.

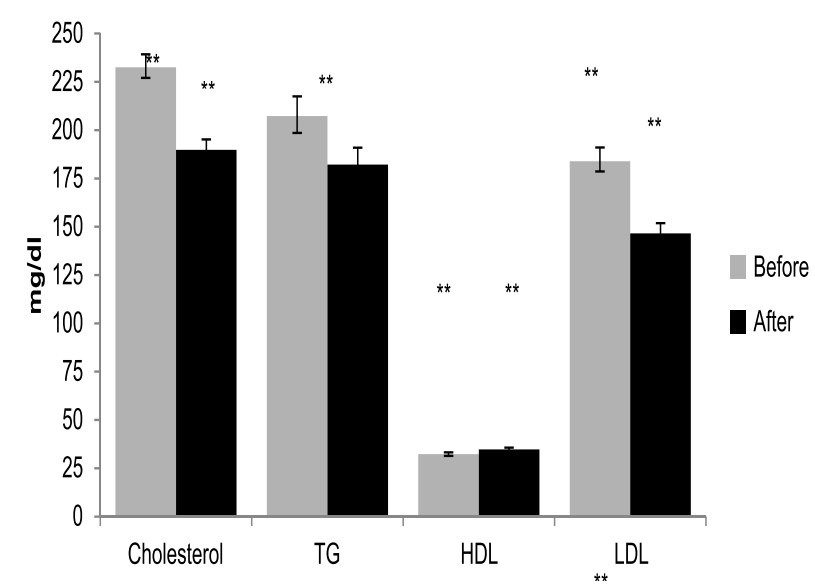

Figure-1: Effects of simvastatin on serum lipid profile in diabetic dyslipidemic patients.

Values are mean \pm s.e $(n=30) .{ }_{* *} p<0.005$ significant difference by t-test as compared to before treatment.

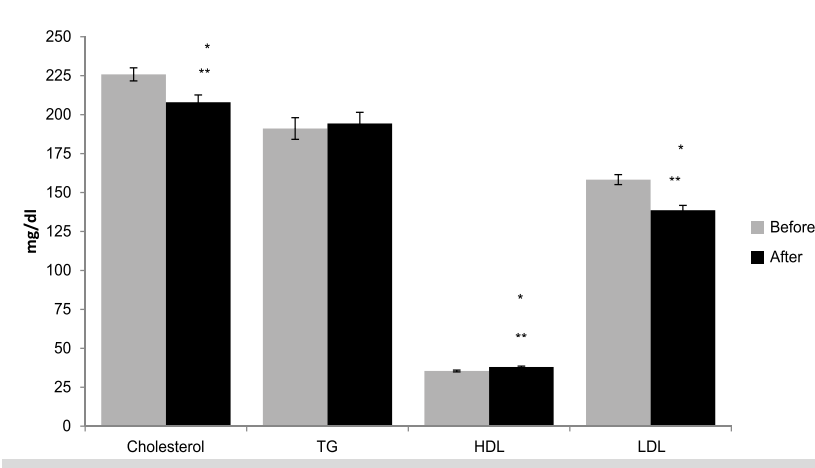

Figure-2: Effects of allium sativum on lipid profile in diabetic dyslipidemic patients.

Values are mean \pm s.e $(n=30) .{ }_{\star} p<0.05$ significant difference by t-test as compared to before treatment.

\section{DISCUSSION}

Predisposing factors like smoking, diabetes and hypertension are strongly linked with cardiovascular related disease among south asia. ${ }^{21}$ In the urbanized life style and higher socio-economic areas, higher incidence of CVD has been reported as compared to lower socioeconomic areas. Hyperlipidemia develops macrovascular disease has a major public health issue in Pakistan. In low-income countries who estimate that the number of mortality due to CVD is rising.

Approximately eighty percent of the casualties caused by macro-vascular disease and $86 \%$ of the global burden of cardiovascular artery disease are in the Pakistan. ${ }^{12}$ Diabetic dyslipidemia is one of the major cause of ischemic heart disease. ${ }^{22}$ Diabetes mellitus is a chronic metabolic disorder affecting around 200 million people worldwide and is responsible for 32 million deaths in a year and by year 2030 its prevalence will be increased to $4.4 \%$. Aside from this, greater than $60 \%$ of the population with diabetes will arise from asia. It has been reported that chronic hyperglycemia of diabetes is linked with dysfunction, damage, and eventually failure of organs.

About $50 \%$ of individuals with diabetes are concerned with one or more of the above complications. $^{2}$ HMG-CoA reductase inhibitors commonly are effective in primary as well as secondary prevention of coronary disease. Therefore, these agents are used as the first 
choice for hypercholesterolemia in this subset of the population, especially simvastatin and atrovastatin.

Simvastatin is an inhibitor of HMG-CoA reductase in the cholesterol synthesis. ${ }^{23}$ As none of the anti-hyperlipidemic agents are devoid of adverse effects, harmful efficient and cost effective agent for managing hyperlipidemia. Therefore the use of plant based herbal medicines have increased considerably over centuries and are becoming a popular alternative management option. ${ }^{24}$ Allium sativum based herbal medicine has proved to decrease many disorders. ${ }^{25}$ Allium sativum and simvastatin are lipid lowering agents. Allium sativum is used around the worldwide. Its beneficial effects on cardiovascular risk factors are widely known but have not been evaluated yet especially in Pakistan. In present study effect of simvastatin on different biochemical parameters along with their lipid lowering efficacy is compare with the effects of allium sativum in diabetic dyslipidemic patients.

In present study when diabetic dyslipidemic patients were treated with product of simvastatin, their serum cholesterol, triglyceride and low density lipoprotein (LDL) were significantly decreased while significant increased has been observed in serum HDL levels after treatment as compared to before treated patients. Treatment with simvastatin for 6 weeks at a dose of $20 \mathrm{mg} /$ day decreases total cholesterol, triglycerides, low-density lipoprotein cholesterol (LDL-C), and increases high-density lipoprotein cholesterol (HDL-C). ${ }^{25}$ Similar changes in lipid profile are evaluated in present study in patients treated with $20 \mathrm{mg}$ simvastatin for 04 months.

Garlic is antioxidant phytochemicals that include organo-sulphur compounds and show hypolipidemic effects on experimentally induced hyperlipidemia. ${ }^{26}$ In diabetic dyslipidemic patients, serum cholesterol and low density lipoprotein were significantly decreased following the treatment of allium sativum while significant increased has been observed in serum high density lipoprotein levels after treatment as compared to before treated patients but there were no significant effects on triglycerides. Long term treatment with garlic is more effective in reducing serum total cholesterol levels and serum triglycerides (TG) levels. ${ }^{27}$ In present study hdlcholesterol concentration significantly increase in addition to decrease in serum total cholesterol and LDL cholesterol concentration observed after 8 weeks treatment of allium sativum. Similar anti-hyperlipidemic effects of garlic also reported previously. ${ }^{28}$ decreased in total cholesterol concentration observed with allium sativum is because of decrease in LDL - cholesterol which is due to blockage of biosynthesis of hepatic cholesterol possibly via inhibition of hydroxyl methylglutaryl coa (HMG-CoA) reductase by allicin, an organo-sulfur constituent of garlic. ${ }^{29}$

\section{CONCLUSION}

Present study was designed to compare the anti-lipidemic effect of allium sativum, a herbal product, with a standard lipid lowering drug, simvastatin. Allium sativum improves lipid profile in diabetic dyslipidemic patients without producing adverse effects as compare to simvastatin and its beneficial effects on cardiovascular risk factors are widely known but have not been evaluated yet specially in Pakistan.

\section{Copyright $\subseteq 15$ Oct, 2019.}

\section{REFERENCES}

1. Aringazina A, Kuandykov T, Arkhipov V. Burden of the cardiovascular diseases in central asia. Cent Asian $\mathrm{J}$ Glob Health. 2018; 7(1): 321.

2. Patti AM, Giglio RV, Papanas N, Rizzo M, Rizvi AA. Future perspectives of the pharmacological management of diabetic dyslipidemia. Expert Rev Clin Pharmacol. 2019; s12 (2):129-143.

3. Márk I, Dani G. Diabetic dyslipidaemia and the atherosclerosis. Orv Hetil. 2016; 157(19):746-52.

4. Elin Yulinah Sukandar, Primal Sudjana, Joseph I. Sigit, NI Putu e. Leliqia and fetri lestari. Safety of garlic (allium sativum) and turmeric (curcuma domestica) extract in comparison with simvastatin on improving lipid profile in dyslipidemia patients. Journal of Medical Sciences, 2013;13: 10-18.

5. Michas G, Karvelas G, Trikas A. Cardiovascular disease in Greece; the latest evidence on risk factors. Hellenic Journal of Cardiology. 2018 Oct 12. 
6. Al-baghli NA, Al-ghamdi AJ, Al-turki KA, El-zubaier AG, Al-mostafa BA, Al-baghli FA, Ai-ameer MM. Awareness of cardiovascular disease in eastern saudi arabia. $J$ Fam Community Med, 2010; 17:15-21.

7. M. Zhao, I. Vaartjes, I. Graham et al., "sex differences in risk factor management of coronary heart disease across three regions," Heart, Vol. 103, No. 20, pp. 1587-1594, 2017.

8. C.-F. Lin, Y.-H. Chang, S.-C. Chien, Y.-H. Lin, and H.Y. Yeh, "Epidemiology of dyslipidemia in the asia pacific region," International Journal of Gerontology, Vol. 12, no. 1, pp. 2-6, 2018.

9. V. J. Ama Moor, S. Ndongo Amougou, S. Ombotto, F. Ntone, D. E. Wouamba, and B. Ngo Nonga, "Dyslipidemia in patients with a cardiovascular risk and disease at the university teaching hospital of yaoundé, cameroon," International Journal of Vascular Medicine, Vol. 2017, Article id 6061306, 5 pages, 2017.

10. Yatsuya $H$, Aaron R. Risk of incident cardiovascular disease among users of smokeless tobacco in the atherosclerosis risk in communities (aric) study, Am J Epidemiol. 2010; 172:600-605.

11. Lavie CJ, Milani RV, Ventura HO. Obesity and cardiovascular disease risk factor, paradox, and impact of weight loss. J Am Coll Cardiol. 2009; 53:1925-1932.

12. Williams ED, Stamatakis E, Chandola T, Hamer M. Physical activity behaviour and coronary heart disease mortality among south asian people in the uk: an observational longitudinal study. Heart. 2011; 97(8):655-9.

13. Siddiqui NA, Perveen T, Kazmi SAJ, Khanum A. Differences in lipoid profile with international product of simvastatin and local product in patient with primary hyperlipidemia. World Journal of Pharmacy and Pharmaceutical Sciences, Vol. 3, no. 8, pp. 2207-2215, 2014.

14. Demir O, Sevimli S, Duman H, Bakirci EM, Hamur $H$. Evaluation of dose efficacy of treatment with atorvastatin, rosuvastatin, and simvastatin in patients with hyperlipidemia. Jam Coll Caediol.2013; 62(18-s2):c182-c182.

15. Le NA, Jin R, Tomassini JE, Tershakovec AM, Neff DR, Wilson PW. Changes in lipoprotein particle number with ezetimibe/simvastatin coadministered with extended-release niacin in hyperlipidemic patients. Journal of the American Heart Association. 2013 Aug 7;2(4):e000037.
16. Stein DT, Devraj S, Adams-huet B, Jialal I. Effect of statin therapy on remnant lipoprotein cholesterol levels in patients with combined hyperlipidemia. Arterioscler Thromb Vasc Biol 2001; 21: 2026-2031.

17. Marcus AO. Lipoid disorders in patients with type 2 diabetes. Postgrad Med 2001; 110: 113-23.

18. Ginter E, Simko V. Garlic (allium sativum I) and cardiovascular diseases. Bratisl Lek Listy. 2010; 111(8): 452-456.

19. Cavagnaro PF, Camargo A, Galmarini CR, Simon PW. Effect of cooking on garlic (allium sativum I.) Antiplatelet activity and thiosulfinates content. J Agric Food Chem. 2007; 55(4): 1280-1288.

20. Metwally MAA. Effects of garlic (allium sativum) on some antioxidant activities in tilapia nilotica (oreochromis niloticus). W J Fish and Marine Sci.2009; 1(1): 56-64.

21. Gardner CD, Lawson LD, Block E, et al. Effect of raw garlic vs commercial garlic supplements on plasma lipid concentrations in adults with moderate hypercholesterolemia: A randomized clinical trial. Arch Intern Med. 2007; 167(4):346-353.

22. Agyemang C, Addo J, Bhopal R, Aikins Ade G, Stronks k. Cardiovascular disease, diabetes and established risk factors among populations of sub-Saharan African descent in Europe: a literature review. Global Health. 2009; 11:5-7.

23. Bianchi C, Miccoli R, Penno G, Del Prato S. Primary prevention of cardiovascular disease in people with dysglycemia. Diabetes Care. 2008; 31(2):s208-14.

24. Stevinson C, Pittler MH, Ernst E. Garlic for treating hypercholesterolemia. A meta-analysis of randomized clinical trials. Ann Intern Med. 2000; 133(6):420-429.

25. Tattelman E. Health effects of garlic. Am Fam Physician. 2005; 72(1).t03-106.

26. Yoon HS, Kim SH, Kim JK, Ko SH, Ko JE, Park SJ. Comparison of effects of morning versus evening administration of ezetimibe/simvastatin on serum cholesterol in patients with primary hypercholesterolemia. Ann Pharmacother. 2011 jul; 45(7-8):841-9.

27. Varsha Gupta. Hyolipidemic effect of garlic: on experimentally induced hyperlipidemia. Jarbs. 2012; 4(1): $5-6$ 
28. Zeng T, Guo FF, Zhang CL, Song FY, Zhao XL, Xie $\mathrm{KQ}$. "A meta-analysis of randomized, double-blind, placebo-controlled trials for the effects of garlic on serum lipid profiles, " Journal of The Science of Food and Agriculture, Vol. 92, No. 9, pp. 1892-1902, 2012.
29. Kojuri J, Vosoughi AR, Akrami M. Effects of anethum graveolens and garlic on lipid profile in hyperlipidemic patients. Lipids Health Dis. 2007; 6: 1-5.

\section{AUTHORSHIP AND CONTRIBUTION DECLARATION}

\begin{tabular}{|c|c|c|c|}
\hline Sr. \# & Author(s) Full Name & Contribution to the paper & Author(s) Signature \\
\hline 1 & Naveed Ali Siddiqui & & 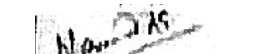 \\
\hline 2 & Fatima Bint Taj & All authors participated & 1 \\
\hline 3 & Imran Ishaque & $\begin{array}{l}\text { equally in bringing the idea, } \\
\text { modifying it, data collection }\end{array}$ & Power \\
\hline 4 & Ayesha Shahid & and writing this article. & $A p^{n+2}$ \\
\hline 5 & Ayesha Ayaz & & \\
\hline
\end{tabular}

